\title{
RESIDUAL ADDUCTION OF THE FOREFOOT IN TREATED CONGENITAL CLUB FOOT
}

\author{
L. W. Lowe and M. A. Hannon, London, England \\ From the Hospital for Sick Children, Great Ormond Street, London
}

Adduction of the forefoot is recognised as one element of the deformity of club foot. It commands little attention because it is one of the less disabling features, and it has been suggested that spontaneous correction eventually occurs (Wynne-Davies 1964).

Metatarsus varus and talo-navicular subluxation, singly or in combination, are the two abnormalities responsible for this deformity. The role of metatarsus varus has not been previously investigated and consequently it is usually regarded as the less important factor.

This survey of older children was undertaken to determine the incidence and cause of residual adduction of the forefoot after various conventional methods of treatment of congenital club foot. We emphasise that cases of congenital metatarsus varus as a separate entity were excluded.

\section{MATERIAL}

A random sample of fifty-one patients was studied. Twenty-two had both feet affected, making a total of seventy-three club feet. The ages ranged from four to fourteen years, with an average of eight years. The lower age limit was dictated by the difficulty in identifying the position of the navicular bone on radiographs in younger children. Four of the feet had received conservative treatment only. The remainder had been subjected to a variety of operations including soft-tissue release, elongation of the tendo calcaneus, crescentic resection, calcaneal osteotomy and the Dillwyn Evans (1961) procedure. In this sample, no operations specifically directed to the correction of metatarsus varus had been performed.

\section{METHOD OF ASSESSMENT}

A clinical assessment of the presence or absence of forefoot adduction was made. Standard antero-posterior radiographs of the foot were taken in a standing position. The position of the navicular in relation to the head of the talus was noted. The estimation of the degree of metatarsus varus proved more difficult and justified a method of measurement. When metatarsus varus is present, its origin lies distal to the navicular, and measurements must therefore relate the position of the first metatarsal to this bone. The base of the navicular is defined by a line joining the extremities of its proximal articular outline. A central line is drawn through the long axis of the first metatarsal. The lateral angle produced by the junction of these two lines is measured and designated the "naviculo-metatarsal angle" (Fig. 1). Both the naviculo-cuneiform and the cuneiform-metatarsal joints contribute to this measurement. We were unable to separate the relative contribution from these two sites; nor did any such distinction seem to have practical value.

Measurement of this type demands the establishment of normal values. Also, the effect on this angle of other aspects of club foot deformity such as inversion and eversion must be assessed. Normal feet were therefore studied to assess these factors.

Control series of normal feet-The naviculo-metatarsal angle was measured on the radiographs of fifty normal feet in children presenting with minor injuries between the ages of four and fourteen years. The average measurement was 93.5 degrees, with close scatter from 86 to 100 degrees. It was therefore considered that values in the series of club feet in excess of 100 degrees 
would represent some degree of metatarsus varus. Further antero-posterior radiographs were taken of six of these structurally normal feet in extremes of inversion and eversion and the measurements were still contained within the original scatter of 86 to 100 degrees. It was therefore considered that fixed deformity in the directions of inversion or eversion in the club foot range would not diminish the accuracy of the measurement.

\section{RESULTS}

On clinical examination of the seventy-three affected feet, forefoot adduction was regarded as present in thirty-eight ( 52 per cent) and absent in thirty-five ( 48 per cent).

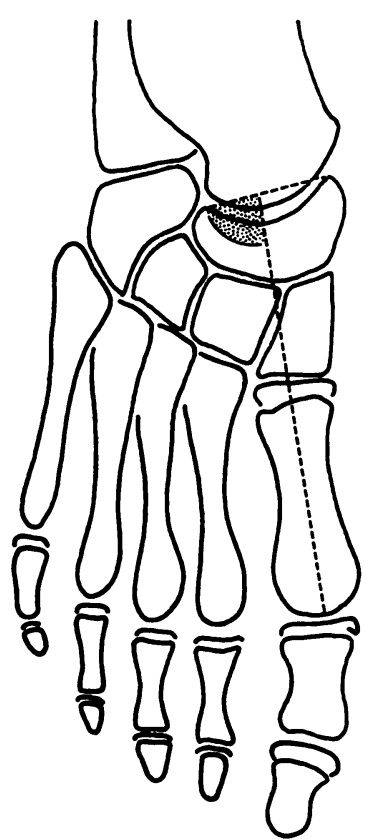

Fig. 1

Diagram of a normal foot to illustrate the "naviculometatarsal angle" (shaded).

The adducted forefoot (thirty-eight feet) - A study of the radiographs identified three causes of the deformity.

Metatarsus varus with a normal talo-navicular joint (Fig. 2)Seventeen feet had a naviculo-metatarsal angle of over 100 degrees, averaging 111 degrees. It was interesting to observe in this group the high incidence of bilateral involvement, which accounted for twelve of the feet.

Metatarsus varus with subluxation of the talo-navicular joint (Fig. 3)-There were eleven feet in this group. The average naviculometatarsal angle was 106 degrees.

Subluxation of the talo-navicular joint alone (Fig. 4)-There were ten feet in this group. The findings were less uniform than in the previous groups, additional features being found. Firstly, two feet had a relative metatarsus valgus with a naviculo-metatarsal angle of 85 degrees. Secondly, three feet showed an outward rotation deformity of the ankle. This was apparent in the lateral radiographs of the foot, which demonstrated a posterior position of the fibula and the appearance of a flat-topped talus (Fig. 5) produced by outward rotation as noted by Swann, Lloyd-Roberts and Catterall (1969). We consider that both features represent spurious correction following attempts to reduce the subluxation of the talonavicular joint.

The non-adducted forefoot (thirty-five feet)-Four groups of radiographic appearances were seen.

No metatarsus varus and a normal talo-navicular joint (Fig. 6)-There were fourteen such feet. The naviculo-metatarsal angle lay within the normal range and averaged 91 degrees.

Metatarsus varus with over-correction of the talo-navicular joint (Fig. 7)-The three feet in this group had naviculo-metatarsal angles of 107, 120 and 109 degrees. However, the forefeet were not adducted because over-correction of the talo-navicular joints had occurred. In two patients this spurious form of correction had followed a Dillwyn Evans operation.

Talo-navicular subluxation with metatarsus valgus (Fig. 8)-The four feet in this group had naviculo-metatarsal angles less than normal, and one was as low as 67 degrees. As a result, there was no adduction of the forefoot despite persisting talo-navicular subluxation.

Talo-navicular subluxation with other forms of spurious correction-In this final group of fourteen non-adducted forefeet, talo-navicular subluxation was compensated by a variety of secondary deformities. In seven feet, outward rotation at the ankle, as mentioned above, was clearly responsible. Three feet had been subjected to tarsal resection with over-correction. The remaining four feet appeared to have been corrected by a combination of mild metatarsus valgus and outward rotation at the ankle.

Alteration of the naviculo-metatarsal angle in club foot with age-Thirty-four feet were of children between four and eight years old and the average naviculo-metatarsal angle was 96.8 degrees. The remaining thirty-nine feet of children between nine and fourteen years old had an average 


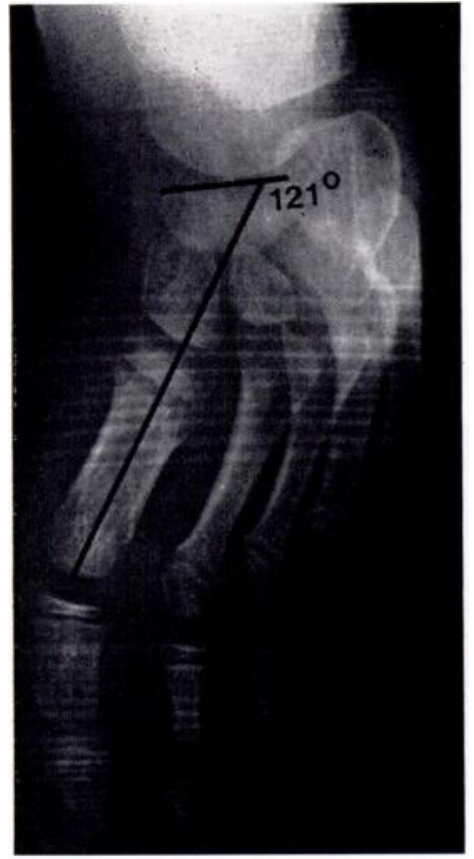

FIG. 2

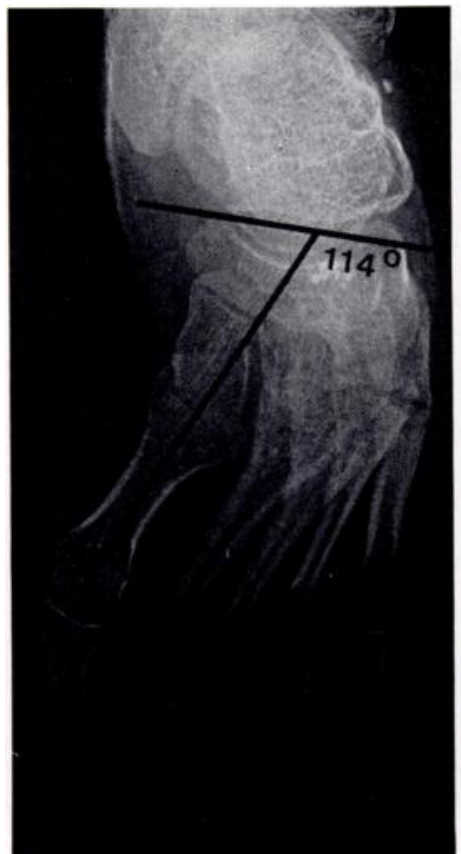

Fig. 3

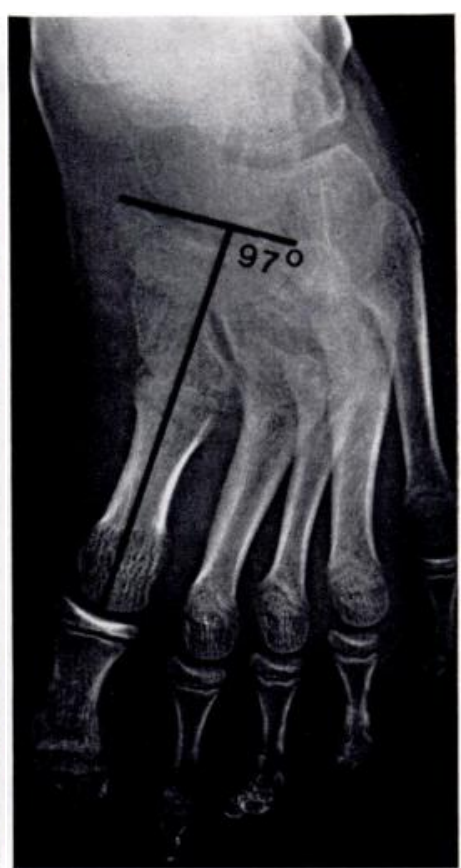

FIG. 4

Figure 2-The radiograph of an adducted foot caused by metatarsus varus. The naviculo-metatarsal angle is 121 degrees. The talo-navicular joint is normal. Figure 3-The radiograph of an adducted foot caused by a combination of talo-navicular subluxation and metatarsus varus. The naviculc-metatarsal angle is 114 degrees. Figure 4-The radiograph of an adducted foot caused by subluxation of the talo-navicular joint. There is no metatarsus varus and the naviculo-metatarsal angle is 97 degrees.

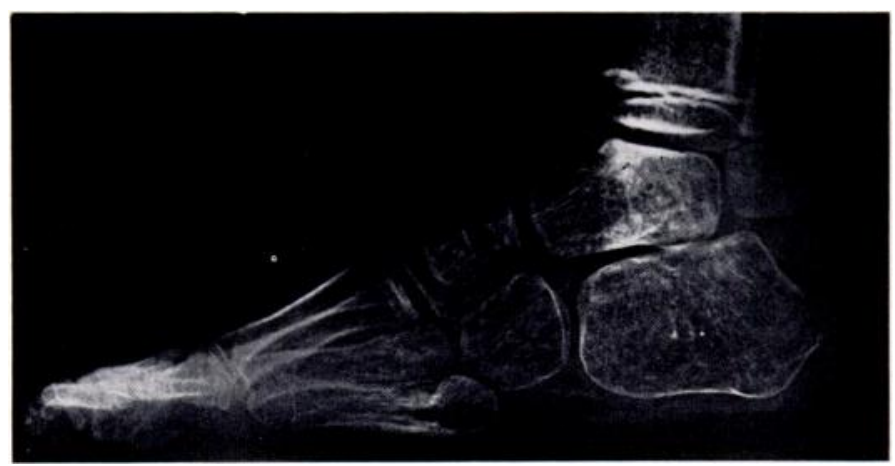

Fig. 5

Lateral radiograph of a foot showing the appearance of a "flat-topped" talus and a posteriorly situated fibula. This is produced by outward rotation of the ankle joint.

angle of 99.8 degrees. This difference, which is away from the expected direction, is far from significant $(P>0.05)$. It suggests, however, that in our patients, metatarsus varus did not correct spontaneously over this particular age span. It is also interesting that the thirty-five feet corrected for adduction were equally distributed in the younger and older age groups (eighteen and seventeen feet respectively).

\section{DISCUSSION}

In this series, forefoot adduction was present on clinical examination in thirty-eight out of seventy-three feet examined, which supports Fripp and Shaw's (1967) observation that 


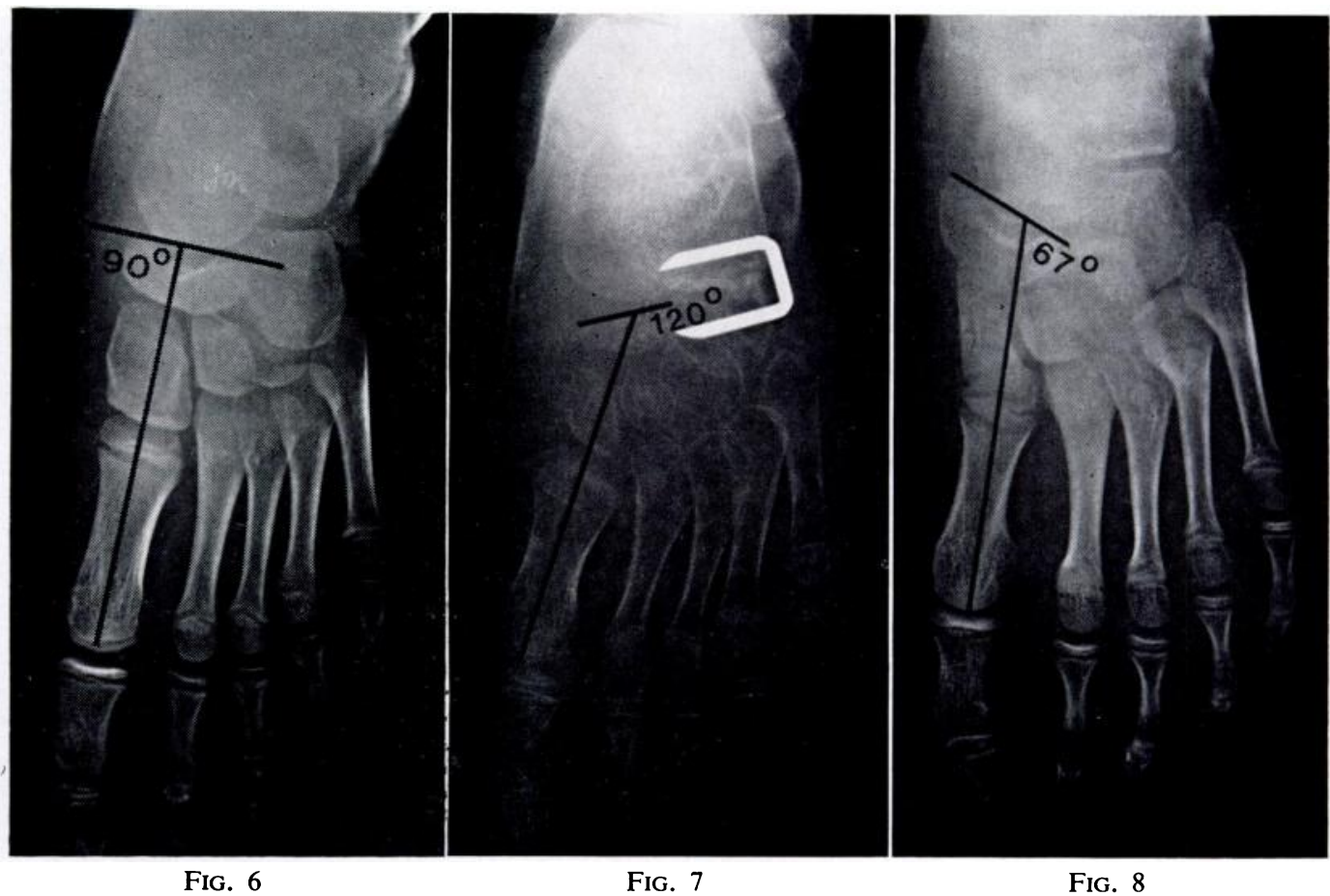

Figure 6-The radiograph of a foot that is not adducted. The talo-navicular joint is normal and there is no metatarsus varus. The naviculo-metatarsal angle is 90 degrees. Figure 7-The radiograph of a foot that is not adducted. Metatarsus varus persists but there is over-correction of the talo-navicular joint after Dillwyn Evans operation. The naviculo-metatarsal angle is 120 degrees. Figure 8-The radiograph of a foot that is not adducted. Talo-navicular subluxation persists but there is over-correction of the metatarsal bones. Metatarsus valgus is present and the naviculo-metatarsal angle is 67 degrees.

forefoot adduction in club foot is undoubtedly present at birth and is often a most persistent deformity. In the adducted group, metatarsus varus alone accounted for 45 per cent, a combination of metatarsus varus and talo-navicular subluxation for 29 per cent, and talonavicular subluxation alone for the remaining 26 per cent. Metatarsus varus therefore emerges as an important factor in 74 per cent when careful assessment by measurement is used. These findings are in marked contrast with those of Wynne-Davies (1964), who did not suspect any patient of having metatarsus varus in a series of 121 older patients reviewed after completion of treatment. When metatarsus varus is part of the club foot deformity, our series suggests that correction does not occur spontaneously with age. On the other hand, Ponseti and Becker (1966) found that when congenital metatarsus varus occurred as an isolated deformity only 11.6 per cent needed definitive treatment. Beatson and Pearson (1966), Wynne-Davies (1964) and others have emphasised the disparity between the clinical and radiological features in relation to the hindfoot. A similar state of affairs exists in respect to the forefoot. Thus, in the foot showing no adduction, radiographs may show 1) normal features; 2) metatarsus varus with over-correction of the talo-navicular joint (particularly after a Dillwyn Evans procedure): 3) talo-navicular subluxation with metatarsus valgus; and 4) talo-navicular subluxation with various forms of spurious correction such as outward rotation of the ankle joint.

Residual adduction of the foot is troublesome because it is responsible for clumsiness of gait and a cosmetic defect which is obvious to the parents. Furthermore, undesirable compensation by outward rotation at the ankle has been seen to occur. More specifically, severe metatarsus varus diminishes the value of the Dillwyn Evans operation and triple arthrodesis in the recalcitrant foot. We suggest that the results of treatment in club foot would 
be improved if more attention were directed to significant metatarsus varus. Attenborough (1966) regarded muscle imbalance between the actively contracting abductor hallucis and the weak peronei as an important feature. On these grounds, it is probably helpful to strip the abductor hallucis from the medial aspect of the heel when carrying out the extended posterior release recommended by Lloyd-Roberts (1971) in the first year of life. Division of the tendon of insertion of this muscle through a separate small distal incision obviates the need to perform an extensive medial dissection of the foot. This reduces the danger of medial tethering from secondary scarring. After the age of three years, nultiple basal metatarsal osteotomies may be helpful.

\section{SUMMARY}

1. Seventy-three congenital club feet in fifty-one children have been reviewed between the ages of four and fourteen years to determine the incidence of residual adduction of the forefoot. 2. A radiological method of measuring metatarsus varus, based on the naviculo-metatarsal angle, is described.

3. On clinical examination 52 per cent of the feet had residual adduction of the forefoot, and metatarsus varus was present in 74 per cent of these.

4. There was no residual adduction in 48 per cent but only 45 per cent of these showed normal radiographic features. In the remainder various forms of spurious correction were seen.

5. For early treatment, detachment of the origin of the abductor hallucis muscle is recommended at the time of extended posterior release, with tenotomy of the tendon of insertion as an additional measure.

We would like to thank Mr G. C. Lloyd-Roberts for his encouragement and advice, the Medical Records Department of the Hospital for Sick Children, and Mr Richard Bowlby (Department of Medical Illustration) and Mr Michael Healy (Computing and Statistics) at Northwick Park Hospital and Clinical Research Centre.

\section{REFERENCES}

Attenborough, C. G. (1966): Severe Congenital Talipes Equinovarus. Journal of Bone and Joint Surgery, 48-B, 31.

Beatson, T. R., and Pearson, J. R. (1966): A Method of Assessing Correction in Club Feet. Journal of Bone and Joint Surgery, 48-B, 40.

Evans, D. (1961): Relapsed Club Foot. Journal of Bone and Joint Surgery, 43-B, 722.

FripP, A. T., and Shaw, N. E. (1967): Club Foot, p. 291. Edinburgh and London: E. \& S. Livingstone Limited.

Lloyd-RoBerTs, G. C. (1971): Orthopaedics in Infancy and Childhood. London: Butterworth \& Co. (Publishers) Ltd.

Ponseti, I. V., and BeCKer, J. R. (1966): Congenital Metatarsus Adductus: The Results of Treatment. Journal of Bone and Joint Surgery, 48-A, 702.

Swann, M., Lloyd-Roberts, G. C., and Catterall, A. (1969): The Anatomy of Uncorrected Club Feet. Journal of Bone and Joint Surgery, 51-B, 263.

Wynne-Davies, R. (1964): Talipes Equinovarus. Journal of Bone and Joint Surgery, 46-B, 464. 